\title{
A WIRELESS-ENABLED RADIATION DETECTOR USING MICROMACHINED STEEL AND GLASS ELEMENTS IN A TO-5 PACKAGE
}

\author{
Christine K. Eun ${ }^{*}$ and Yogesh B. Gianchandani* ${ }^{*}$
}

Department of Electrical Engineering and Computer Science, University of Michigan, Ann Arbor, USA

\begin{abstract}
This paper reports a beta/gamma radiation detector that is manufactured by in-package assembly of micromachined stainless steel and glass elements. The detector is hermetically-sealed at 760 Torr with an Ar fill-gas. Gas micro-discharges (between the steel elements) are triggered by the presence of radiation, which can concomitantly transmit a wideband wireless signal. The detector diameter and height are $9 \mathrm{~mm}$ and $9.6 \mathrm{~mm}$, respectively, and has a mass of $0.97 \mathrm{~g}$. It has a measured output of $>100 \mathrm{cpm}$ when in close proximity to $30 \mu \mathrm{Ci}$ from ${ }^{137} \mathrm{Cs}$. Wireless spectra spanning $1.25 \mathrm{GHz}$ at receiving antenna-to-detector distances $>89$ $\mathrm{cm}$ have been measured, with the device detecting $0.1 \mu \mathrm{Ci}$ from ${ }^{90} \mathrm{Sr}$ and operating with a portable high-voltage conversion circuit.
\end{abstract}

\section{INTRODUCTION}

Sensing beta and gamma radiation is important for many homeland security applications. These forms of radiation have appreciable travel range and are also generated by most radiation sources of interest. Gas $\mu$ discharge-based radiation detection offers low dark current, temperature insensitivity, avalanche-driven signal amplification, and the ability to detect a wide range of radiation energies [1]. We have previously reported Marconibased transmission using micromachined test structures [2]. Miniaturized wireless-enabled radiation sensors could someday be used in easily redeployable or mobile network configurations [3,4].

\section{DEVICE CONCEPTS AND OPERATION}

The detector structure includes a stacked pair of steel electrodes, and insulating glass elements, that are hermeticallypackaged inside a fill-gas (Fig. 1). The steel elements (Layers 2a and 4a) are perforated and separated by a glass spacer (Layer 3), which defines the anode-cathode gap spacing. The interspacers lie in-plane with the electrode to provide protection against spurious discharges near high-field regions between the steel elements and pins. An applied field generates high-field regions near the perforations. Beta radiation passes through the perforations and directly interacts with the fill-gas, whereas gamma radiation mostly interacts with the steel electrodes to generate photoelectrons. Beta radiation or photoelectrons initiate current-

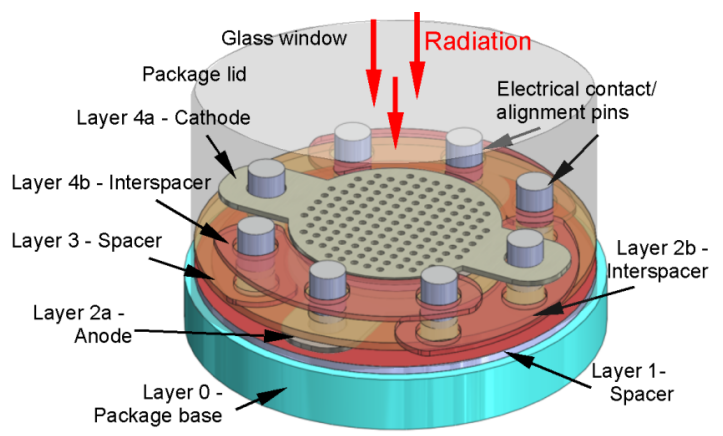

Figure 1: The detector comprises a stacked arrangement of stainless steel electrodes (Layers 2a, 4a) and glass insulators (Layers 1,3) assembled within a commercial TO-5 package base. Layer 3 defines the electrode gap spacing. Radiation triggers avalanche within the biased gap, which leads to wireless signaling. driven avalanche pulses between the biased electrodes, which transmit wideband wireless signals.

\section{FABRICATION \& ASSEMBLY}

The detector elements are manufactured by commercial processes. To fabricate the electrodes (Fig. 2a), dry photoresist is laminated on $125 \mu \mathrm{m}$-thick stainless steel (302/304). Following double-sided lithography, the sample is through-etched by a hot etchant spray. In this particular design, $125 \mu \mathrm{m}$-diameter circular perforations are formed, with $250 \mu \mathrm{m}$ center-to-center spacing. The glass spacer elements are fabricated using a micro-abrasive jet process (Fig. 2b). A protective masking layer is lithographicallypatterned on a $150 \mu$ m-thick borosilicate glass substrate. An abrasive powder mixed with compressed air is sprayed onto the surface, chiseling the desired pattern. The interspacers are machined similarly. A $22^{\circ}$ sidewall results from this process. To facilitate assembly, each element (steel or glass) is designed with alignment openings to line up with the package pins.

The package is an 8-pin TO-5 metal can package of $9 \mathrm{~mm}$ diameter and $9.6 \mathrm{~mm}$ height. It comprises a nickel base and a lid composed of a Kovar body with a $750 \mu \mathrm{m}$-thick glass (Corning 7052) window. Electrical feed-throughs are available as pins through the package base. First, a glass spacer is assembled for electrical insulation (Fig. 3a), followed by the anode that is flanked by a pair of interspacers (Fig. 3b). Next, another glass spacer is installed, defining the electrode gap spacing, followed by the

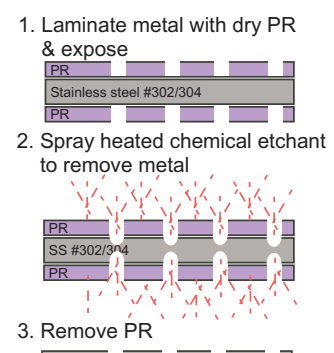

(a) Remove PR

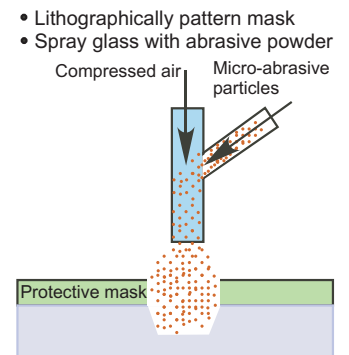

(b) Borosilicate glass

Figure 2: Fabrication process for (a) photochemically-etched electrodes and (b) powder-blasted glass spacers.
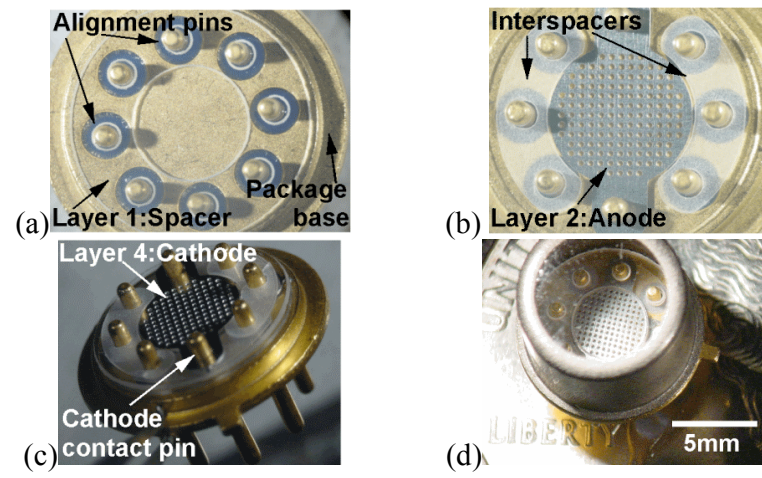

Figure 3: Microassembly of the detector. (a) A glass insulator is positioned onto the base. (b) Followed by the anode and interspacers, (c) Next, the electrode gap defining spacer and then the cathode and interspacers. (d) The hermetically-sealed device. 


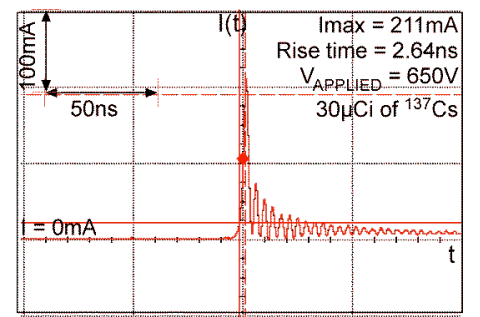

Figure 4: Current pulse measurement (of a "count") using a high-frequency inductive current probe attached to the cathode shows approximately $200 \mathrm{~mA}$ peaks and 50-100 ns duration.

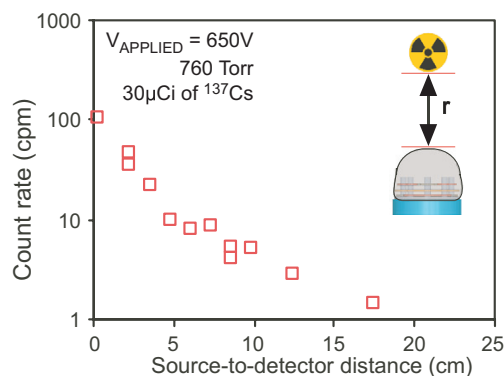

Figure 5: Wired measurement. Count rates decrease logarithmically with increasing source-to-detector distance, $r$. The source and detector are axially aligned and moved vertically.

cathode that is flanked by a pair of interspacers (Fig. 3c). After assembly, the package is hermetically-sealed at 760 Torr with an Ar fill-gas, using a commercial resistance projection welding process (Fig. 3d). The overall device weighs $<1 \mathrm{~g}$.

\section{RESULTS AND DISCUSSION}

The hermetically-sealed device was characterized using radioisotope sources of $30 \mu \mathrm{Ci}{ }^{137} \mathrm{Cs}$ (which emits beta and gamma radiation) and $0.1 \mu \mathrm{Ci}{ }^{90} \mathrm{Sr}$ (a pure beta-emitter).

Wired measurements The count rate was measured with a high-frequency inductive current probe. At $650 \mathrm{~V}$ bias, current pulses with $50-100 \mathrm{~ns}$ duration and up to $100 \mathrm{cpm}$ frequency were observed (Fig.4). Pulse rates were correlated to separation from the radioisotope, $r$ (Fig. 5). The measured background rates (in the absence of the radiation source) were $1.3 \mathrm{cpm}$.

Wireless measurements The wireless spectra transmitted by the device were measured inside an anechoic chamber using a 200 MHz-1 GHz log-periodic antenna (EMCO 93146) connected to a spectrum analyzer (HP8563E). In order to increase portability, a high-voltage flash circuit modified from a disposable camera was coupled to the detector (Fig. 6). Additionally, the drive circuit included an RC timing circuit and ballast resistors. During detector operation (in the presence of ${ }^{90} \mathrm{Sr}$ ), wireless spectra were observed to span $1.25 \mathrm{GHz}$ with peaks at $550 \mathrm{MHz}, 750 \mathrm{MHz}$, and $1.1 \mathrm{GHz}$. The received signal power decreased with increasing antenna-detector distances, $d$ (Fig. 7). For these measurements, $V_{\text {APPLIED }}$ was $2.8 \mathrm{~V}$, leading to $670-680 \mathrm{~V}$ at the device.)

\section{CONCLUSIONS}

A wireless-enabled micromachined radiation detector manufactured using in-package assembly methods has been presented. The device generated count rates $>100 \mathrm{cpm}$ and transmitted wideband wireless spectra spanning $>1.25 \mathrm{GHz}$. The device is powered using a portable high-voltage conversion circuit. The overall detector and power module (excluding battery) weighs $0.97 \mathrm{~g}$ and $7.9 \mathrm{~g}$, respectively, which can enable future portable, reconfigurable networks of wireless radiation sensors. (a)

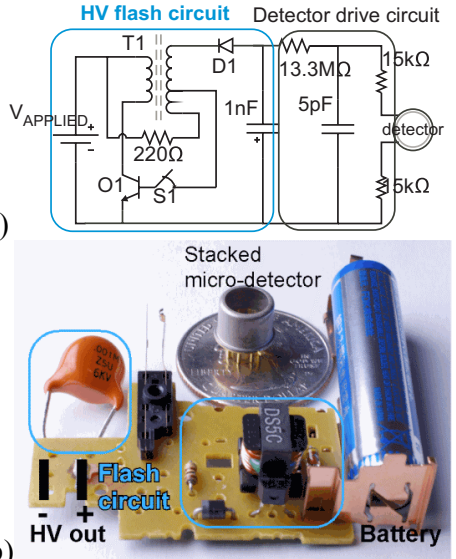

Figure 6: (a) Schematic of the high-voltage flash circuit and the detector drive circuit. (b) Photo of a battery-operated highvoltage supply adapted from the flash circuit board of a disposable camera.

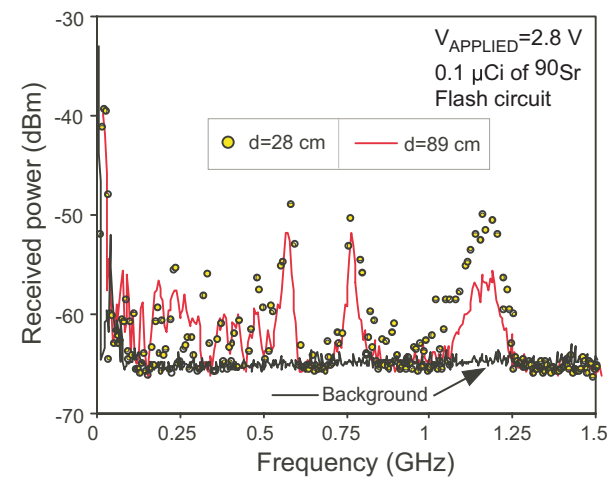

Figure 7: Wireless measurement. Wireless spectra measured inside an anechoic chamber spans $1.25 \mathrm{GHz}$, with peaks at 550 $\mathrm{MHz}, 750 \mathrm{MHz}$, and $1.1 \mathrm{GHz}$. $V_{A P P L I E D}=2.8 \mathrm{~V}$. The received wireless power decreases with increasing antenna-detector distance. Strong signaling was observed at distances $>89 \mathrm{~cm}$.

\section{ACKNOWLEDGEMENTS}

This work was supported by the Dept. of the Army, Micro Autonomous Systems and Technology (MAST) Collaborative Technology Alliance, Contract No. W911NF-08-2-0004. The authors thank Prof. Sarabandi, Dr. Adib Nashashibi, and Prof Gharpurey for collaboration on the signaling concept.

\section{REFERENCES}

[1] G.F. Knoll, Radiation Detection and Measurement, John Wiley and Sons, 2000.

[2] C.K. Eun, Y.B. Gianchandani, "A Micromachined Wireless Gamma Radiation Detector Using Bulk Metal Conversion Layers," Solid-State \& Actuator Workshop, Hilton Head Isl, SC, (2008) pp. 308-311.

[3] R.J. Nemzek et al., "Distributed sensor networks for detection of mobile radioactive sources," IEEE Trans. on Nuclear Science, vol. 51, no. 4, Aug. 2004, pp. 1693-1700.

[4] R. Kyker et al., "Hybrid Emergency Radiation Detection (HERD), a wireless sensor network application for consequence management of a radiological release," Proceedings of SPIE, vol. 5440, pp. 293-304.

\section{CONTACT}

*C.K. Eun tel: +1-734-763-6132; eunc@umich.edu

**Y.B. Gianchandani tel: +1-734-615-6407; yogesh@umich.edu 